\title{
Estimation of Crop Evapotranspiration in North of Shanxi Province
}

\author{
Qiubo Long \\ Institute of Geographic Sciences and Natural Resources Research, \\ Chinese Academy of Sciences, \\ Beijing, 100101, China; \\ Hunan Hydro \& Power design institute, Changsha, 416000, China
}

\begin{abstract}
Seven representative empirical potential evapotranspiration equations selected form the radiationbased and temperature-based methods, they were evaluated and compared with the Penman-Montieth equation using daily meteorological data form Mizhi station in north of Shanxi. The comparison was first made using original constant values involved in each empirical equation and then using the recalibrated constant values, the study showed that: the original constant values involved in each empirical equation performed badly except the equation of modified Makkink and Hargreaves, the mean error was larger than 15\%; Improvement was achieved for each empirical equation though the parameter recalibration by genetic algorithm, good correlation was found between the ETO values estimated by each empirical equation and the Penman-Montieth equation, the performance of radiationbased methods was better than temperature-based in accuracy and correlation, obviously. The Gaoqiao equation was recommended to calculate the ETO for the study region in the temperature-based methods, its mean error was less than $10 \%$. Estimated by Prestley-Taylor and modified Makkink equation were in closest agreement with PM reference crop evapotranspiration, the mean error was less than $3 \%$, which equation was chosen depending on the meteorological data or measured data
\end{abstract}

Keywords: Mizhi, crop evapotranspiration, parameter recalibration, Penman-Montieth equation.

\section{INTRODUCTION}

Evapotranspiration is an important component of water balance system and is foundation for crop water requirement research, agricultural irrigation, engineering design and water resource management. Estimating of evapotranspiration usually adopts two stage of processing [1]. The first step is to estimate potential evapotranspiration, then through the crop, soil moisture and other factors to calculate the actual evapotranspiration. Potential evapotranspiration of vegetation coverage area is usually calculated with reference crop evapotranspiration (ET0). According to different meteorological data, reference crop evapotranspiration method consists of temperature method, radiation method and comprehensive method. Penman-Montieth method (PM), as a standard method to calculate the reference crop evapotranspiration recommended by the FAQ [2], has been applied widely in the world. It is considered as standard method for ET calculation and evaluation of other methods in area where lacking of observed data [3-5]. However, PenmanMontieth method requires much meteorological data, including solar radiation, temperature, humidity and wind speed data. So it can hardly be applied in absence of one or several meteorological data.

In this case, the evapotranspiration calculation method based on temperature, radiation, humidity can be used to replace Penman-Montieth formula to calculate the reference crop evapotranspiration. A lot of research has done about the applicability evaluation of these methods in different regions. Amatya [6] uses PM formula as standard method and analyzes ET results in Northeast Carolina with rest five kinds of empirical formula; based on temperature, radiation, comprehensive method and quality transfer method etc., Xu and Singh [7] selects five representative methods and calculates ET0 of the Swedish Changins meteorological station. Domestic scholars such as Liu Xiaoying [8], Peng Shizhang [9], Fan Jun [10] also carried out similar research. It was concluded that the method based on radiation is generally better than temperature calculation method. But optimal application of these methods is varied due to regional climatic characteristics. In order to test the applicability of different empirical methods in north of Shanxi province, we took Penman-Montieth formula results as standard and evaluated ET calculation method, which three are representative based on temperature and four are based on radiation, hope to provide reference for ET calculation lack of data.

\section{DATA AND METHOD}

\section{A. Study area}

The study area is located in Mizhi County of Shaanxi Province; belong to typical gully region of Loess Plateau. It is in the temperate semi-arid climate zone, the annual average temperature is of 8.4 degrees Celsius, the extreme maximum temperature can reach 38 degrees and the extreme minimum temperature can go down to -24 degrees. The annual sunshine duration is around $2761 \mathrm{~h}$. Meteorological station located in Mizhi County (E110 $10^{\prime}$, $\left.\mathrm{N} 37^{\circ} 45^{\prime}\right)$. Its altitude is about $867.2 \mathrm{~m}$. To compute ET in this area, the meteorological data of the main growing period of 2009 is selected, the specific data is listed in table 1 . 
TABLE 1: TEN DAYS MEAN METEOROLOGICAL DATA FROM MAY TO OCTOBER, 2009, MIZHI

\begin{tabular}{|c|c|c|c|c|c|c|c|c|c|}
\hline Date & 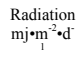 & $\begin{array}{l}\text { Aver- } \\
\text { Temp } \\
{ }^{\circ} \mathrm{C}\end{array}$ & $\begin{array}{l}\text { Max- } \\
\text { Temp } \\
{ }^{\circ} \mathrm{C}\end{array}$ & $\begin{array}{l}\text { Min- } \\
\text { Temp }{ }^{\circ} \mathrm{C}\end{array}$ & $\begin{array}{c}\text { Max- } \\
\text { Humidity\% }\end{array}$ & $\begin{array}{c}\text { Min- } \\
\text { Humidity } \\
\%\end{array}$ & $\begin{array}{c}\text { Aver- } \\
\text { Humidity \% }\end{array}$ & $\begin{array}{c}\text { W- } \\
\text { Speed } \\
\mathrm{m} / \mathrm{s}\end{array}$ & $\begin{array}{l}\text { Precipitation } \\
\mathrm{mm}\end{array}$ \\
\hline $\begin{array}{l}5.5- \\
5.14\end{array}$ & 10.31 & 16.28 & 21.6 & 10.15 & 82.65 & 24.21 & 54.25 & 2.54 & 15.2 \\
\hline $\begin{array}{l}5.15- \\
5.28\end{array}$ & 11.96 & 17.65 & 26.37 & 12.24 & 72.34 & 15.85 & 52.18 & 2.10 & 2.8 \\
\hline $\begin{array}{c}5.29- \\
6.7\end{array}$ & 13.96 & 19.64 & 27.87 & 12.54 & 77.65 & 14.91 & 50.65 & 1.24 & 1.2 \\
\hline $\begin{array}{l}6.8- \\
6.17\end{array}$ & 14.13 & 21.89 & 28.33 & 14.55 & 71.23 & 14.53 & 45.21 & 0.81 & 0 \\
\hline $\begin{array}{l}6.17- \\
6.26\end{array}$ & 13.73 & 22.75 & 29.11 & 14.34 & 74.30 & 18.28 & 51.32 & 1.51 & 5.4 \\
\hline $\begin{array}{l}6.26- \\
7.5\end{array}$ & 14.78 & 23.95 & 30.59 & 16.89 & 82.65 & 24.25 & 58.64 & 0.68 & 12.3 \\
\hline $\begin{array}{l}7.6- \\
7.15\end{array}$ & 15.13 & 24.65 & 31.56 & 17.72 & 86.57 & 30.67 & 59.79 & 1.85 & 21.4 \\
\hline $\begin{array}{l}7.16- \\
7.25\end{array}$ & 13.98 & 25.36 & 32.43 & 19.32 & 89.68 & 31.02 & 62.71 & 1.58 & 36.4 \\
\hline $\begin{array}{c}7.26- \\
8.4\end{array}$ & 14.03 & 23.72 & 29.54 & 18.76 & 87.24 & 34.26 & 61.74 & 1.94 & 29.7 \\
\hline $\begin{array}{l}8.5- \\
8.14\end{array}$ & 15.59 & 23.97 & 31.89 & 16.95 & 81.28 & 24.16 & 51.59 & 1.48 & 7.2 \\
\hline $\begin{array}{l}8.15- \\
8.24\end{array}$ & 8.57 & 19.97 & 24.91 & 16.08 & 94.76 & 54.07 & 77.32 & 1.36 & 116.8 \\
\hline $\begin{array}{c}8.25- \\
9.3\end{array}$ & 12.85 & 20.55 & 26.33 & 15.90 & 88.80 & 41.27 & 66.33 & 2.14 & 19.2 \\
\hline $\begin{array}{l}9.4- \\
9.13\end{array}$ & 5.84 & 16.26 & 19.69 & 13.45 & 97.66 & 63.81 & 84.41 & 0.83 & 62 \\
\hline $\begin{array}{l}9.14- \\
9.23\end{array}$ & 13.46 & 16.95 & 24.84 & 9.77 & 93.85 & 24.55 & 62.67 & 1.61 & 6.8 \\
\hline $\begin{array}{c}9.24- \\
10.3\end{array}$ & 13.67 & 17.72 & 26.47 & 10.32 & 92.30 & 16.95 & 56.83 & 1.40 & 2.8 \\
\hline
\end{tabular}

B. Method

Penman-Montieth method [2]

By defining standard crop, FAQ provides a formula to solve problem of impedance coefficient in PenmanMontieth formula:

$$
E T_{0}=\frac{0.408 \Delta\left(R_{n}-G\right)+\gamma \frac{900}{T+273} u_{2}\left(e_{s}-e_{a}\right)}{\Delta+\gamma\left(1+0.34 u_{2}\right)}
$$

Where ET0 is reference evapotranspiration $(\mathrm{mm} / \mathrm{d}) ; \mathrm{T}$ is average temperature $(\mathrm{oC}) ; \gamma$ is saturated vapor pressure curve slope $(\mathrm{kPa} / \mathrm{oC}) ; \Delta$ is psychomotor constant $(\mathrm{kPa} / 0 \mathrm{C})$, which can be obtained by elevation calculation; $\mathrm{Rn}$ is net solar radiation $(\mathrm{MJ} \bullet \mathrm{m}-2 \cdot \mathrm{d}-1) ; \mathrm{G}$ is the soil heat flux $(\mathrm{MJ} \bullet \mathrm{m}-2 \cdot \mathrm{d}-1)$; $\mathrm{u} 2$ is wind speed around two meters above ground; es and ea is saturated vapor pressure and the actual water vapor pressure $(\mathrm{kPa})$ respectively.

\section{Temperature-based method for ET}

i) Hargreaves method[11]

Hargreaves and Samin (1982, 1985) improved the function promoted by Hargreaves, in which astronomical radiation ( $\mathrm{Ra}$ ) and $\mathrm{TD}$, difference of maximum temperature and minimum temperature, are introduced to evaluate solar radiation (Rs):

$$
E T_{0}=\partial \operatorname{RaTD}^{1 / 2}(T+17.8)
$$

Where $\partial$ is empirical parameter and its value is 0.0023 ; $\mathrm{Ra}$ is astronomical radiation $(\mathrm{mm} / \mathrm{d})$; $\mathrm{TD}$ is difference of maximum temperature and minimum temperature.

ii) Gaoqiao method[12]

Gaoqiao formula has a definite physical basis, which is a semi-theoretical and semi-empirical formula for worldwide average watershed month evapotranspiration.
According to annual energy balance and water balance principle, experience coefficient can be determined by integration. This formula verified properly through measured data from around the world.

$$
E T_{0}=\frac{\partial \exp \left(\frac{17.2 T}{235+T}\right)}{1+0.01 P \exp \left(-\frac{17.2 T}{235+T}\right)}
$$

Where $\mathrm{P}$ is average precipitation $(\mathrm{mm}) ; \partial$ is empirical parameter, $\partial=13$.

iii) Linacre method[13]

In 1997, Linacre estimated potential evapotranspiration through a series of assumptions to simplify the Penman equation.

$$
E T_{0}=\frac{\partial T_{m} /(100-A)+15\left(T-T_{d}\right)}{80-T}
$$

Where $\partial$ is empirical parameter, $\partial=500$; $\mathrm{Tm}=\mathrm{T}+0.006 \mathrm{~h}, \mathrm{~h}$ is elevation data; $\mathrm{A}$ is latitude data; $\mathrm{Td}$ is average dew point temperature.

\section{Radiation-based method for ET}

Method of solar radiation-based evapotranspiration estimation of land surface is widely used. Many empirical formulas are proposed based on this method and some of which relates to temperature.

i) Makkink method[14]

Makkink (1957) presented ten days' evapotranspiration estimating method under cold climate conditions in Holland, then Hasen[15], according to actual survey data, revised the Makkink formula and proposed the following formula:

$$
E T_{0}=\partial \frac{\Delta}{\Delta+\gamma} \frac{R s}{\lambda}
$$

Where the is energy coefficient, Rs is solar radiation $(\mathrm{MJ} \cdot \mathrm{m}-2 \cdot \mathrm{d}-1) ; \lambda$ is latent heat of vaporization $(\mathrm{MJ} / \mathrm{kg})$.

ii) Jensen-Haise method[16]

By studying 35 years' data from 3000 evapotranspiration station, Jensen and Haise introduced formula below:

$$
E T_{0}=\frac{C_{t}\left(T-T_{x}\right) R_{s}}{\lambda}
$$

Where the $\mathrm{Ct}$ is a temperature constant and its value is 0.025 in original formula; the value of TX is -3 .

iii) Hargreaves method

Based on analyzing eight years' grassland leakage data, Hargreaves and Samin [17] put forward several methods to calculate potential evapotranspiration, one of which is:

$$
E T_{0}=\frac{\partial(T+17.8) R_{s}}{\lambda}
$$

Where the $\partial$ is empirical parameter, which is 0.0135 in original formula. 
iv) Priestley-Taylor method[18]

In 1972, Priestley and Taylor simplified the PenmanMontieth formula under surface humid condition:

$$
E T_{0}=\partial \frac{\Delta}{\Delta+\gamma} \frac{R_{n}}{\lambda}
$$

Where the $\partial$ is energy coefficient.

\section{RESULTS AND ANALYSIS}

\section{A. Results}

Based on formula (1) (8) and original formula parameters, reference crop evapotranspiration from May to October in 2009 of Mizhi county was obtained. Temperature and radiation based ET calculation results are shown in Fig.1 2 and the average error is shown in table 2 .

From fig.1-2 and tab.2, it shows that the ET results of temperature-based method and radiation-based method aren't ideal; errors are almost above $20 \%$. Its results are smaller than the PM formula, which denotes that temperature-based method is generally superior to radiation-based method. Among temperature-based methods, the result of Hargreaves is the best, while in radiation-based method, the results of Prestley-Taylor method is much closer to PM method. Error of Makkink is the maximum. The primitive formula experience parameters are generally small.

The empirical parameters of original formula are obtained under specific climate environment, when being used in other area, parameters recalibration must be pay attention to [10].

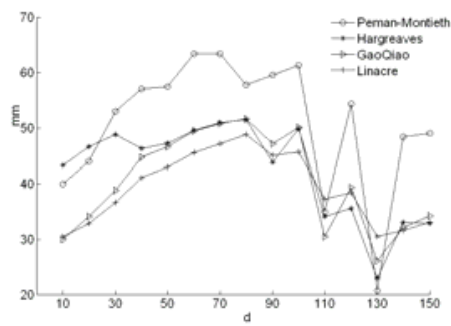

Fig. 1: Comparison of ET values between temperature-based and PM methods using original constant

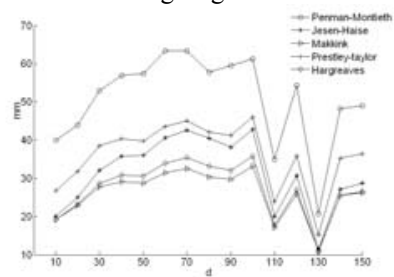

Fig. 2: Comparison of ET values between radiation-based and PM methods using original constant values

\section{B. Calibration}

\section{Calibration method}

Inner genetic algorithm of MATLAB is introduced for parameter correction. According to minimum of variance sum principle, function of genetic algorithm can be constructed:

$$
\text { fitness }=\sum\left(E T_{P M}-E T_{\mathrm{TR}}\right)^{2}
$$

Where fitness is the fitness function of genetic algorithm; ETPM is calculation result of PM formula; ETTR is calculation of temperature-based method and radiation-based method. The results of parameter optimization are shown in fig.3, fig. 4 , table. 2 .

From fig. 3 and fig.4, it showed obviously that ET results after parameter modification has been improved and the result of radiation-based is more close to the PM method. Within the temptation-based method, the Gaoqiao formula's results are closest to the PM method, but there are some extreme points or mutations. After parameter correction, the radiation-based method of ET calculation is very close to PM formula and the extreme point or mutations also accord with the result of PM method.

TABLE 2: THE STATISTICAL ANALYSIS BETWEEN EMPIRICAL EQUATION AND PM EQUATION BEFORE AND AFTER RECALIBRATION CONSTANT

\begin{tabular}{|c|c|c|c|c|c|c|c|}
\hline \multirow{2}{*}{$\begin{array}{c}\text { Mean error } \\
(\%)\end{array}$} & \multicolumn{3}{|c|}{ Temperature-based method for $\mathrm{ET}_{0}$} & \multicolumn{4}{|c|}{ Radiation-based method for $\mathrm{ET}_{0}$} \\
\hline & Hargreaves & Gaoqiao & Linacre & Makkink & $\begin{array}{l}\text { Jesen- } \\
\text { Haise }\end{array}$ & Hargreaves & $\begin{array}{c}\text { Prestley- } \\
\text { Taylor }\end{array}$ \\
\hline original & 17.90 & 22.47 & 25.64 & 48.83 & 39.20 & 46.48 & 29.08 \\
\hline recalibrated & 14.16 & 9.60 & 15.19 & 8.61 & 9.81 & 5.06 & 4.53 \\
\hline
\end{tabular}
VALUES

TABLE 3: COMPARISON OF PARAMETER VALUES BEFORE AND AFTER RECALIBRATION CONSTANT VALUES

\begin{tabular}{cccccccc}
\hline & \multicolumn{2}{c}{ Temperature-based method for ET } & \multicolumn{4}{c}{ Radiation-based method for ET } \\
\cline { 2 - 7 } Method & Hargreaves & Gaoqiao & Linacre & Makkink & $\begin{array}{c}\text { Jesen- } \\
\text { Haise }\end{array}$ & Hargreaves & $\begin{array}{c}\text { Prestley- } \\
\text { Taylor }\end{array}$ \\
\hline $\begin{array}{c}\text { Original } \\
\text { parameter }\end{array}$ & 0.0023 & 31 & 500 & 0.7 & 0.025 & 0.0135 & 1.26 \\
$\begin{array}{c}\text { Recalibrated } \\
\text { parameter }\end{array}$ & 0.0032 & 39 & 650 & 1.25 & 0.038 & 0.0243 & 1.65 \\
\hline
\end{tabular}

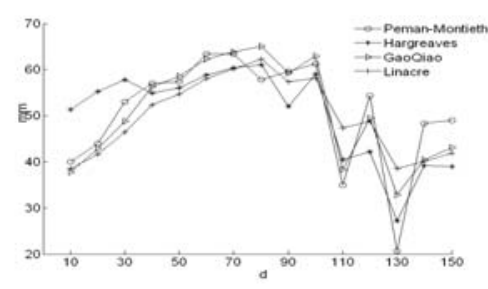

Fig. 3 Comparison of ET values between temperature-based and PM methods after recalibration constant 


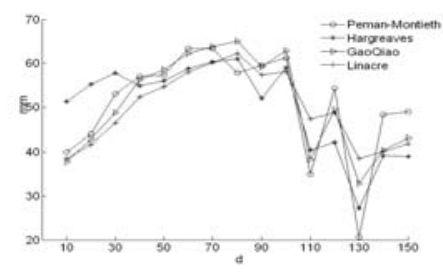

Fig. 4: Comparison of ET values between radiation-based and PM methods after recalibration constant

Average error and correlation among formula and PM method are all improved after parameters correction. Correlation coefficient of all method is above 0.92 . What's more, the correlation coefficient of radiationbased method and PM method is obviously higher than the temperature-based method, which is close to 0.99 .

The error comparison shows that calculation error of temperature-based method is generally larger, except error of Gaoqiao formula $(9.8443 \%)$ is less than $10 \%$. The error of other two methods is more than $10 \%$ and the error of Hargreaves method is $12.4463 \%$. Radiation-based method, in contrary, the average error is less than $5 \%$, except the relative error of Jesen-Haise formula is greater than $5 \%$. The Prestley-Taylor formula and PM formula calculation result is very close and the average error is $2.9517 \%$. The average error of Makkink formula and Hargreaves formula is also small, respectively $2.9678 \%$ and $3.4036 \%$.

\section{CONCLUSIONS}

This paper takes the PM method as standard and evaluates ET that based on three kinds of temperature, four kinds of radiation. Conclusions can be drawn as follow:

i) Except Makkink formula, ET results of temperature method and radiation method by using original parameters are not ideal, which must be calibrated using local weather or measured data.

ii) Precision and correlation of the two methods are both improved obviously after modifying parameters by genetic algorithm. What's more, precision of radiation method is significantly better than the temperature method. Within temperature method, Gaoqiao formula is recommended. As to radiation method, the PrestleyTaylor results are close to modified Makkink methods which are both reasonable. We can select proper one according to actual data.

iii) Due to data limitation, we merely calculated ET from May to October in 2009. If possible, it is advised to do more research based on enough meteorology data, which is useful for these formulas' application in the study area.

\section{REFERENCES}

[1] Maidment. D. R. Handbook of hydrology, translated by Zhan Jianyun, Li Jisheng, et al. Beijing: Science press, 2002.

[2] Allen R. G, Pereira. L. S, Raes. D, Smith, M. Crop evapotranspiration -guidelines for computing crop water requirements. FAO irrigation and drainage paper 56, FAO - Food and Agriculture Organization of the United Nations Rome, 1998.
[3] Irmak. S, Allen. R. G, Whity. E. B. Daily grass and alfalfareference evapotranspiration estimates and alfalfa-to-grass evapotranspiration ratio in Florida. Journal of Irrigation and Drainage Engineering, 2003, 129(5): 360-370.

[4] Trajkoric. S. Temperature-base approaches for estimating reference evapotranspiration. Journal of Irrigation and Drainage Engineering, 2005, 131(4): 316-325.

[5] Fan Chen, Robinson. P. J. Estimating reference crop evapotranspiration with Etgages. Journal of Irrigation and Drainage Engineering, 2009, 135(3): 335-342.

[6] Amatya. D. M, Skaggs. R. W., Gregory. J. D. Comparison of methods for estimating REF-ET. Journal of Irrigation and Drainage Engineering, 1995, 121(6): 427-435.

[7] Xu. C. Y, Singh. V. P. Cross comparison of empirical equations for calculating potential evapotranspiration with data from Switzerland. Water Resources Management, 2002, 16: 197-219.

[8] Liu Xiaoying, Lin Erda, Liu Peijun. Comparative study on Priestley-Taylor and Penman methods in calculating reference crop evapotranspiration. Transactions of The Chinese Society of Agricultural Engineering, 2003, 19(1):51-55.

[9] Peng Shizhang, Xu Junzeng,.Comparison of reference crop evapotranspiration computing methods .Journal of Irrigation and Drainage, 2004, 23(6): 5-9.

[10] Fan Jun, Shao Ming'an, Wang Quanjiu. Comparison of many equations for calculating reference evapotranspiration in the Loess Plateau of China. Transactions of The Chinese Society of Agricultural Engineering, 2008, 24(3):98-102.

[11] Hargreaves. G. H. Accuracy of estimated reference crop evapotranspiration. Journal of Irrigation and Drainage Engineering, 1989, 115(6): 1000-1007.

[12] Zhang Jishi, Chen Rensheng, Lv Shihua, et al. Physical hydrology. Zhengzhou, Yellow River conservancy press, 2007.

[13] Linarce. E.T.A simple formula for estimating evaporation rates in various climates using temperature data alone .Agricultural Meteorology, 1977, (18): 409-424.

[14] Makkink. G. F. Testing the Penman formula by means of lysimeters. Journal of Institution of Water Engineering, 1957, (11): 277-288.

[15] Hansen. Estimating of potential and actual evapotranspiration. Nordic Hydrology, 1984, 15(4): 205-212.

[16] Jesen. M. E, Haise. H. R. Estimating of evapotranspiration form solar radiation. Journal of Irrigation and Drainage Engineering, 1963, (89): 15-41.

[17] Hargreaves. G. H, Samni, Z. A. Estimating potential evapotranspiration. Journal of Irrigation and Drainage Engineering, 1982, 108(3): 225-230.

[18] Priestley-Taylor. H. B, Taylor. R. J. On the assessment of surface heat flux and evaporation using large-scale parameters .Monthly Weather Review, 1972, 100: 81-92. 